\title{
Spinal Tanycytic Ependymoma Associated With Neurofibromatosis Type 2
}

\author{
-Case Report- \\ Keisuke UEKI, Tomio SASAKI, Tsuyoshi ISHIDA*, and Takaaki KIRINO \\ Departments of Neurosurgery and ${ }^{*}$ Pathology, The University of Tokyo Hospital, Tokyo
}

\begin{abstract}
An 18-year-old girl with a 5-year history of neurofibromatosis type 2, consisting of bilateral acoustic tumors and meningioma at the planum sphenoidale, presented with an intramedullary mass at the $T-1$ level, and underwent total removal of the tumor. Histological examination showed that the tumor consisted of markedly elongated spindle-shaped cells, which were immunopositive for S-100 protein and glial fibrillary acidic protein. Ultrastructural examination showed microvilli-lined lumina and prominent intercellular junctions, which were characteristic ependymal features. These findings were compatible with the diagnosis of tanycytic ependymoma. This rare subtype of ependymoma appears to arise through inactivation of $\mathrm{NF2}$, in addition to some typical ependymomas.
\end{abstract}

Key words: spinal tumor, tanycytic ependymoma, neurofibromatosis type 2, chromosome 22

\section{Introduction}

Tanycytic ependymomas are a rare subtype of ependymomas, which were formally recognized as a pathological entity in the latest World Health Organization classification..$^{5)}$ The term "tanycytic" was used because the morphology mimics tanycytes, a distinct type of embryonic ependymal cells that develops in parallel with epithelial ependymocytes. ${ }^{6)}$ In addition to providing insights into the origins of ependymomas, the rare morphology of this type can potentially be misinterpreted as pilocytic astrocytomas or other tumors showing elongated cells. Here we report a case of tanycytic ependymoma in the spinal cord which arose in a patient with neurofibromatosis type 2 .

\section{Case Report}

A 13-year-old girl was found to have neurofibromatosis type 2, when magnetic resonance (MR) imaging demonstrated bilateral acoustic tumors and a meningioma at the planum sphenoidale. She underwent gamma knife radiosurgery for the left acoustic tumor, which caused total hearing loss on that side. Three years later, she underwent total removal of the right acoustic tumor, which was histologically con-

Received April 11, 2001; Accepted August 9, 2001 firmed as a schwannoma, followed by gamma knife radiosurgery for the planum sphenoidale meningioma. The right side hearing remained intact after surgery. MR imaging of the spine performed at age of 18 years revealed multiple intradural extramedullary nodules measuring $1-2 \mathrm{~mm}$ in diameter and a $3 \times$ $12 \mathrm{~mm}$ intramedullary tumor at the T-1 level. The intramedullary tumor showed rapid growth after 6 months and reached $1 \times 4 \mathrm{~cm}$ in size extending from the C-7 to T-2 levels, accompanied by a syrinx extending both rostrally and caudally (Fig. 1). Neurological examination demonstrated slightly exaggerated bilateral knee jerks, but no sensory disturbance. The left hearing loss was unchanged. Surgical resection of the intramedullary tumor was recommended considering the rapid growth, and the patient was referred to our neurosurgical service.

A C-7 to T-2 laminectomy was preformed. The dorsal surface of the swollen spinal cord was covered with abnormally enlarged venous channels. A midline incision was made on the dorsal surface of the spinal cord at the T-1 level, which immediately exposed a grayish, soft, and avascular tumor. The tumor margin was discrete in most directions except for the rostral and caudal ends, where the attachments of the tumor to the spinal cord were relatively unclear. The tumor was totally removed en bloc. She developed hypesthesia below the T-4 level after sur- 


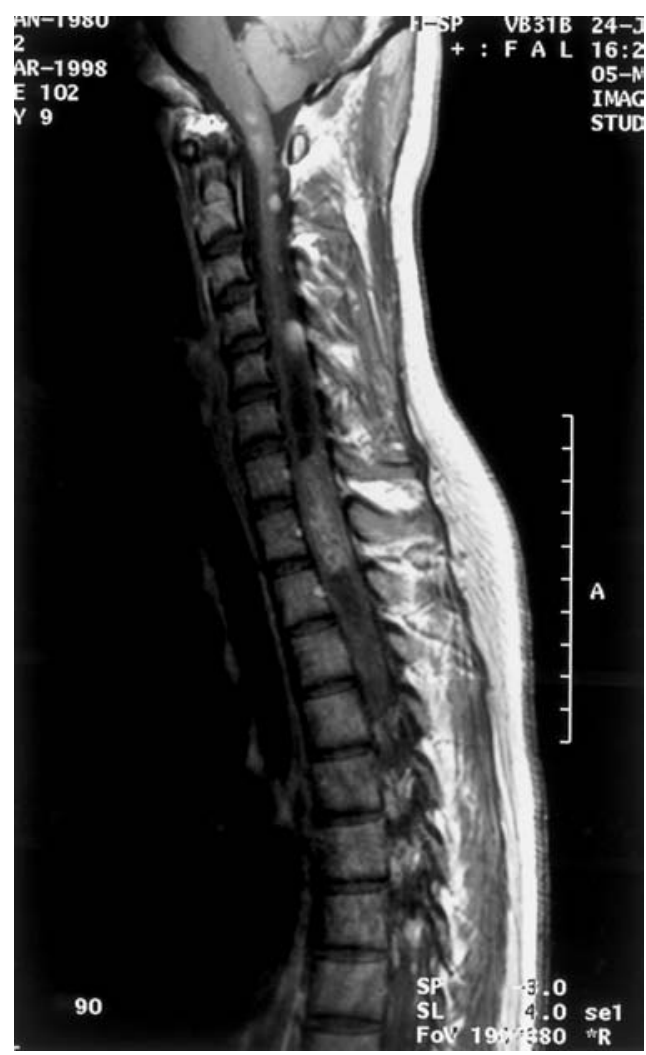

Fig. 1 Sagittal $T_{1}$-weighted magnetic resonance image with gadolinium-diethylenetriaminepenta-acetic acid showing an intramedullary tumor at C7-T2 with syrinx.

gery, which had resolved completely one month later when she was discharged.

Histological examination of the tumor found elongated cells with highly fibrillary processes forming a fascicular architecture, and paucicellular areas with inconspicuous perivascular pseudorosettes. No Rosenthal fibers were observed (Fig. 2A, B). The tumor cells showed immunopositivity for S-100 protein, and occasionally for glial fibrillary acidic protein (Fig. 2C). Electron microscopy showed characteristic ependymal features such as intracytoplasmic intermediate filaments, prominent intercellular junctions, and microvilli-lined lumina (Fig. 2D). These findings were compatible with the diagnosis of tanycytic ependymoma. ${ }^{6}$

\section{Discussion}

The low incidence of tanycytic ependymomas and their histology atypical for ependymomas can cause a diagnostic problem. The elongated cells with rich fibrillary processes resemble pilocytic astrocytomas, schwannomas, or fibroblastic meningiomas. ${ }^{1,4)}$
Schwannomas and meningiomas are the two major central nervous system neoplasms associated with neurofibromatosis type 2 , but intramedullary schwannomas or meningiomas can be included in the differential diagnosis, although they are also extremely rare. When an obvious intramedullary tumor showing spindle-shaped cells on frozen section is encountered, tanycytic ependymomas should be considered. In such a situation, ultrastructural examination is essential to identify ependymal cell features such as microvilli and intercellular junctions. ${ }^{6)}$ The definitive diagnosis of tanycytic ependymoma is extremely difficult to make using frozen sections. Therefore, an index of suspicion for this rare subtype of ependymomas is important to support decision making during surgery. Our case indicates that such an index could be helpful in the management of patients with neurofibromatosis type 2. Postoperative management can also be affected by the diagnosis, because radiation therapy is a treatment option for ependymomas but not for schwannomas or pilocytic astrocytomas. On the other hand, whether tanycytic ependymomas should be treated similarly to the common ependymomas or not is still unknown, because of the very small number of reported cases.

The tumor suppressor gene NF2 located at 22q12 was identified as the gene responsible for neurofibromatosis type 2, which encodes a cytoskeleton-related protein merlin. Extensive investigations showed that inactivation of NF2 is involved in the tumorigenesis of many neoplasms including schwannomas, meningiomas, mesotheliomas, and ependymomas. ${ }^{7,9)}$ Mutation of NF2 was detected in only some ependymomas, ranging from $10 \%$ to $35 \%,^{8)}$ in contrast to the much higher frequency in schwannomas of 50-70\%. ${ }^{3)}$ Interestingly, the majority of NF2 mutations in ependymomas are found in spinal lesions, suggesting a more significant link between spinal ependymoma and NF2. ${ }^{2,8}$ ) Although we did not directly prove the mutation of the NF2 gene, the obvious clinical diagnosis of neurofibromatosis type 2 in this patient strongly suggests that inactivation of NF2 is involved in the tumorigenesis of this rare type of ependymoma. An interesting open question is whether there is any difference in the frequency of NF2 alteration between the subtypes of ependymomas, which awaits further accumulation of cases with molecular genetic data.

\section{Acknowledgment}

We thank Mr. S. Fukuda for his excellent assistance in electron microscopy. 

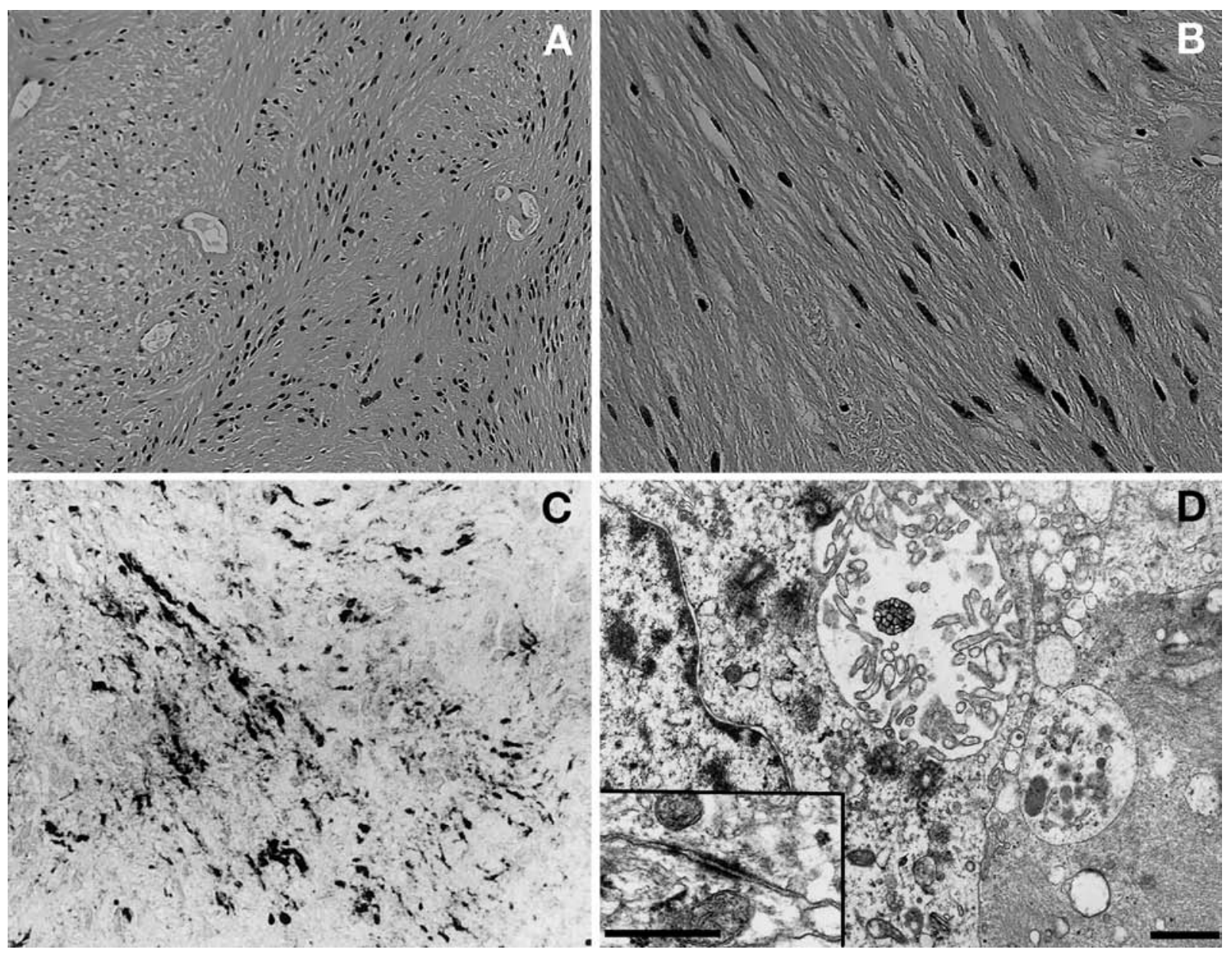

Fig. 2 Histological examination of the tumor. A-C: Photomicrographs showing the tumor consisting of elongated cells with highly fibrillary processes, forming a fascicular architecture, and of paucicellular area with inconspicuous perivascular pseudorosettes (HE stain, A: $\times 40, \mathrm{~B}$ : $\times$ 200), and the elongated cytoplasmic processes are immunopositive for glial fibrillary acidic protein (C: $\times 100)$. D: Electron micrographs showing cytoplasmic lumina with many microvillous projections. Desmosome-like intercellular junctional structures are frequently observed (inset). Each bar indicates $0.5 \mu \mathrm{m}$.

This work was supported by a Grant-in-Aid from the Ministry of Education, Science, Sports and Culture, Japan (No. 11671357 and No. 13470184), and a Grant-in-Aid from Research Foundation of Cell Science.

\section{References}

1) Burger PC, Scheithauer BW: Tumours of the Central Nervous System. Washington, DC, AFIP, 1993, pp 125-126

2) Ebert C, von Haken M, Meyer-Puttlitz B, Wiestler OD, Reifenberger G, Pietsch T, von Deimling A: Molecular genetic analysis of ependymal tumors. NF2 mutations and chromosome 22q loss occur preferentially in intramedullary spinal ependymomas. Am J Pathol 155:
627-632, 1999

3) Jacoby LB, MacCollin M, Louis DN, Mohney T, Rubio MP, Pulaski K, Trofatter JA, Kley N, Seizinger B, Ramesh V, Gusella JF: Exon scanning for mutation of the NF2 gene in schwannomas. Hum Mol Genet 3: 413-419, 1994

4) Kawano N, Yagishita S, Hara M, Tadokoro M: Pathologic features of ependymoma: Histological pattern and a review of the literature. Neuropathology 18: 1-12, 1998

5) Kleihues P, Cavenee WK: WHO Classification; Tumors of the Central Nervous System. Lyon, IARC, 2000, pp $72-73$

6) Langford LA, Barre GM: Tanycytic ependymoma. Ultrastruct Pathol 21: 135-142, 1997

7) Rouleau GA, Merel P, Lutchman M, Sanson M, Zucman J, Marineau C, Hoang-Xuan K, Demczuk S, 
Desmaze C, Plougastel B, Pulst SM, Lenoir G, Bijlsma E, Fashold R, Dumanski J, de Jong P, Parry D, Eldrige R, Aurias A, Delatre O, Thomas G: Alteration in a new gene encoding a putative membrane-organizing protein causes neuro-fibromatosis type 2. Nature 363: 515-521, 1993

8) Rubio MP, Correa KM, Ramesh V, MacCollin MM, Jacoby LB, von Deimling A, Gusella JF, Louis DN: Analysis of the neurofibromatosis 2 gene in human ependymomas and astrocytomas. Cancer Res 54: 45-47, 1994

9) Trofatter JA, MacCollin MM, Rutter JL, Murrell JR,
Duyao MP, Parry DM, Eldridge R, Kley N, Menon AG, Pulaski K, Haase VH, Ambrose CM, Munroe D, Bove C, Haines JL, Martuza RL, MacDonald ME, Seizinger BR, Short P, Buckler AJ, Gusella JF: A novel moesin-, ezrin-, radixin-like gene is a candidate for the neurofibromatosis 2 tumor suppressor. Cell 75: 826, 1993

Address reprint requests to: K. Ueki, M.D., Department of Neurosurgery, The University of Tokyo Hospital, 7-3-1 Hongo, Bunkyo-ku, Tokyo 113-8655, Japan. 